\title{
In Silico Bioactive Peptide Prediction from The Enzymatic Hydrolysates of Edible Seaweed Rubisco Large Chain
}

\author{
Ayse Kose ${ }^{1, *}$ (1) \\ ${ }^{1}$ Ege University Faculty of Engineering Department of Bioengineering, 35100, Bornova, Izmir, Turkey.
}

\begin{abstract}
How to cite
Kose, A. (2021). In Silico Bioactive Peptide Prediction from The Enzymatic Hydrolysates of Edible Seaweed Rubisco Large Chain. Turkish Journal of Fisheries and Aquatic Sciences, 21, 615-625. http://doi.org/10.4194/1303-2712-v21_12_04
\end{abstract}

\section{Article History}

Received 02 June 2021

Accepted 11 August 2021

First Online 13 August 2021

Corresponding Author

Tel.: +902323115811

E-mail: ayse.kose@ege.edu.tr

\section{Keywords}

Bioactive peptides

Functional foods

In silico

Macroalgae

RubisCO

\begin{abstract}
Seaweeds are one of the ancient food supplements on Earth. Especially Asian countries use seaweeds as the fundamental ingredient in their cuisine. Seaweeds are photosynthetic organisms living in aquatic ecosystems and in the coastal territories. Seaweeds out of farm areas are frequently observed as coastal wastes. However, seaweeds are outstanding sources for bioactive substances and investigation bioactive properties of seaweed RuBisCO has never been done. RuBisCO is the most abundant protein on Earth but a vast amount of RuBisCO goes through waste. In this study, bioactive peptide prediction of frequently consumed seaweed RuBisCO proteins were analyzed in silico to identify possible bioactive peptides as substitute or support for grain, meat, and dairy based bioactive peptides. A huge portion of peptides were di-, tri- peptides with $\mathrm{IC}_{50}$ values less than $300 \mu \mathrm{M}$ according to the comparison of BIOPEP database. Including gastric digestion, more than half of the peptides showed DDP-IV and ACE inhibitory activity followed by antioxidant properties. Also, novel antiinflammatory and anti-cancer peptides were found through in silico analysis.
\end{abstract}

\section{Introduction}

Proteins have been major food supplement on human nutrition. Humans consume proteins from grains like wheat, rice, beans, lentil, chickpea, soy, meat products from poultry, aquaculture or red meat industry and dairy products like milk, yoghurt, cheese, whey etc. which are rich in protein content (FitzGerald et al., 2019). These sources of proteins are valuable because the cryptic bioactive peptides are embedded in mother protein and only shows intrinsic activities when the mother protein is degraded via enzymatic processes through digestive system (Fan et al., 2014).
Bioactive peptides obtained from marine, plant, dairy and meat sources show various bioactivities such as antioxidant, antihypertensive, immunomodulatory, anticancer, anti-diabetic (Yanhong Li et al., 2008; Yunliang Li et al., 2015; Tejano et al., 2019; Udenigwe et al., 2017a). The health benefits and their potential on providing a healthy diet and potential to prevent chronic diseases made them a new attraction for functional nutrition and therapeutics (Onuh et al., 2014). Besides, they are derived from natural sources, reliable and sustainable supplements comparing them with synthetic origins. Idea of taking nutritional supplements then medicine is also a more positive image considering 
the psychological choices of the individuals (Kose \& Oncel, 2015b).

Bioactive peptides are 2-20 amino acid chain length short oligopeptides (Morris et al., 2008; Wijesekara et al., 2011). They can be synthesized synthetically, produced by recombination techniques (Liang et al., 2014) or obtained from various extraction methods like chemical, enzyme treatment and fermentation (Udenigwe et al., 2017a). Exogenous and endogenous peptidases and proteases can serve to decode these bioactive peptides through natural digestion, fermentation or other industrial processes which are mild process conditions compared to other physical techniques (Udenigwe et al., 2013).

The bioactivity of a peptide is highly dependent on the length and combination of the amino acids which defines their molecular mass, solubility and interaction at aqueous environment, net charge on the peptide and most importantly bioactivity to be defined (Agyei et al., 2018; Udenigwe et al., 2013). If enzymatic hydrolysis is going to be used, the choice of the enzyme is also an important parameter to optimize. Each enzyme has a various recognition site to cut the protein. This affects the total length, molecular mass, amino acid sequence and other physicochemical and bioactivity characteristics of the peptides in the mixture. As novel pharmaceutical compounds, peptides catch attention as dietary medicine due to low toxicity and their significant function (Zhou et al., 2013). Recently, sports food, special nutrition supplements contain bioactive peptides after understanding outstanding bioactivities of peptide hydrolysates.

Macroalgae, also known as seaweeds, has been one of the main food supplements in Asian countries; Japan, Korea, China, Philippines being the leaders on mass production and consumption. There are various species known with high nutritional values currently available even local markets. The physiochemical properties, protein, carbohydrates, pigment, vitamin, mineral and fiber content attribute to a balanced nutrition. The protein content is changeable, brown seaweeds are usually low in protein yield in comparison to green and red seaweeds. As a local and traditional food source the bioactive peptides inside seaweeds are of importance for deciphering cryptic bioactive peptides.

Ribulose-1,5-bisphosphate carboxylase/oxygenase (RuBisCO, E.C. 4.1.1.39) is one of the mostly expressed enzymes various autotrophic organisms as algae (microalgae and seaweeds), bacteria (photosynthetic and chemoautotrophic bacteria, cyanobacteria, archaea) and plants (Udenigwe et al., 2017a). RuBisCO is responsible from the catalytically conversion of $\mathrm{CO}_{2}$ to organic carbon sources in Calvin-Benson Cycle (Udenigwe et al., 2017a). The primary sequence of the RuBisCO known to be conserved among species, but it is also visible that the amino acid composition and length of the protein may show difference which can be considered as a clue for evolutionary adaptations.
RuBisCO is directly related to crop yield, photosynthetic efficiency, mineral and water usage of the organisms and the major contributor of the global carbon cycle. RuBisCO is documented to have bioactive peptides for the treatment of various chronic illnesses from cardiovascular to neurodegenerative diseases and oxidative stress related physiological malfunctions (Selvaraj et al., 2017). It is one of the most abundant proteins on Earth (Udenigwe et al., 2017a). RuBisCO consumption thus probability of consumed bioactive peptides derived from RuBisCO is also higher as well along with diet as naturally.

Computational tools can be applied to mining bioactive peptides from various sources (Udenigwe et al., 2013). Common webservers are developed for in silico peptide prediction and mostly angiotensin converting enzyme (ACE), dipeptidyl peptidase (DPP)-IV and antioxidant peptides could be deciphered from various sources rich in protein (Gu et al., 2011; Lafarga et al., 2015; Nongonierma \& Fitzgerald, 2014). Udenigwe et al. (2013) showed DPP-IV, ACE, and antioxidant activities of several RuBisCO proteins from common cereals utilized. Selveraj et al. (2017) showed the bioactive peptide prediction from commercially edible microalgae species RuBisCO. However, even though seaweeds are also a major food sources there is no data for in silico peptide prediction considering seaweeds as protein sources especially RuBisCO utilization in functional food industry is highly demanding.

The aim of this study is to draw a scheme using computational in silico tools for novel peptide prediction from most consumed edible seaweed species using RuBisCO as mother protein. Combination of bioactive peptides, distribution, predicted bioactivity, anticancer and toxic properties are computed using ExPASy, BIOPEP, UniProt, ToxinPred, iCAP, iACP, AntiCP, MLACP and Bioware webservers. The anti-inflammatory peptide prediction was done using AlPred. The study is valuable output for further synthesis of synthetic analogs of bioactive peptides or recombinant production for the detection of actual bioactivities.

\section{Materials and Methods}

\section{Sequences of Seaweed RuBisCO}

Edible seaweeds; Undaria pinnatifida, Sargassum fusiforme, Fucus vesiculosus, Rhodymenia palmate, Ulva lactuca, Laminaria japonica (Sargassum japonica), Mastocarpus stellatus (Gigartina stellata), Ulva intestinalis (Enteromorpha intestinalis), Gracilaria edulis, Porphyra umbilicalis, Callophyllis variegate species were selected according to their consumption and biotechnological importance. RuBisCO large subunit accession numbers were obtained from UniProtKB/Swiss-Prot and TrEMBL databases for primary amino acid sequences for further analysis (Table 1). RuBisCO large Chain ( $r b c L$ ) sequences were used only 
because there were not enough data for all the species RuBisCO Small Chain (rbcS).

\section{Multiple Sequence Alignments (MSAs)}

The amino acid concentration from each protein was calculated using ProtParam Tool (http://web.expasy.org/protparam/) to compute physicochemical properties of RuBisCO proteins through amino acid sequences. Multiple sequence alignments (MSAs) were done with ClustalW2 (http://www.clustal.org/clustal2/) and phylogenetic tree was constructed using Clustal Omega. Seaweed RuBisCO sequence alignments were done in comparison to several conventional edible plants Oryza sativa (P0C512), Hordeum vulgare (P05698), Triticum aestivum (P11383), Zea mays (P00874) Avena sativa (P48684) RuBisCO large chain (Udenigwe et al., 2013).

\section{In Silico Analysis}

The enzymatic hydrolysis was achieved using BIOPEP Web server (http://www.uwm.edu.pl/biochemi a/index.php/en/biopep). The database provides enzymatic hydrolysis, bioactivity prediction and comparison of possible achieved peptides in their databases (Minkiewicz P. et al., 2008). The frequency of occurrence of susceptible bioactive peptides in seaweed RuBisCO was calculated using BIOPEP. Industrially utilized proteases such as thermolysin (EC 3.4.24.27) and papain (EC 3.4.22.2) were chosen for in silico peptide prediction from enzyme(s) action of BIOPEP web server. The crude protein hydrolysates were analyzed for their possible bioactivities such as ACE inhibition, antioxidative capacity, DPP-IV inhibition, and so on based on the calculated bioactivity prediction scores.

Due to common utilization of these seaweeds as food sources, simulated gastric digestion was also done in BIOPEP server. Simulated Gastrointestinal (GI) digestion was carried out for RuBisCO proteins as well. Protein and peptide sequences were evaluated for potential cleavage by $\mathrm{Gl}$ enzymes (pepsin, $\mathrm{pH}=1.3$ ), trypsin (EC 3.4.21.4) and chymotrypsin (EC3.4.21.1). The potential bioactivities of the peptides were analyzed using PeptideRanker and peptide score was calculated using 0.5 as threshold (http://bioware.ucd.ie/ compass /biowareweb/).

The probable toxic peptides were predicted using ToxinPred,

http://www.imtech.res.in/raghava/toxinpred/ (Gupta et al., 2013). Anticancer peptide prediction was done according to iACP (Chen et al., 2016), AntiACP (Tyagi et al.,2013) and MLACP (http://thegleelab.org/MLACP.ht $\mathrm{ml}$ ) databases. Peptides giving 0.5 and higher probability on Peptide Ranker further analyzed for antiinflammatory prediction using AIPred (http://thegleela b.org/Alpred.html).

\section{Results and Discussion}

\section{Investigation of Seaweed RuBisCO}

RuBisCO is correspondent to a major portion of protein in plants and algae and still is the most abundant protein on Earth (Udenigwe et al., 2017b). The increasing attention on empowering rural economies also effects the algae cultivation and investments. Development of seaweed-based industries is a part of circular economy where sustainable utilization of existing resources becoming an urgent topic day by day due to increasing crisis on food and fuel debate. Algae as a major food supplement and food ingredient spreads from Asia to Europe and other parts of the world as a new hype oriental food source (Fleurence et al., 2018). Increase in the consumption of algae species makes them a major attention for novel functional food search. Thus, the bioactive peptide encrypted in the seaweed is of importance.

Table 1. List of seaweeds utilized for in silico peptide determination

\begin{tabular}{|c|c|c|c|c|c|c|}
\hline $\begin{array}{l}\text { UniProt Accession } \\
\text { Number }\end{array}$ & $\begin{array}{c}\text { Number of } \\
\text { amino acid } \\
\text { residues }\end{array}$ & $\begin{array}{l}\text { Protein } \\
\text { size }(\mathrm{kDa})\end{array}$ & $\begin{array}{c}\text { Theoretical } \\
\text { PI }\end{array}$ & $\begin{array}{c}\text { Grand Average of } \\
\text { Hydropathy } \\
\text { (GRAVY) }\end{array}$ & Organisms & $\begin{array}{l}\text { Traditional } \\
\text { name }\end{array}$ \\
\hline A0A220NUZ6 & 488 & 48.08 & 5.58 & -0.034 & Sargassum fusiforme & Hijiki \\
\hline AOA0R6M8Y2 & 488 & 54.07 & 5.71 & -0.079 & Undaria pinnatifida & Wakame \\
\hline Q2PQH5 & 488 & 53.94 & 5.52 & -0.105 & Fucus vesiculosus & Bladderwrack \\
\hline Q9THF8 & 488 & 54 & 5.54 & -0.141 & Rhodymenia palmata & Dulse \\
\hline Q7Y838 & 445 & 49.06 & 6.26 & -0.283 & Ulva lactuca & Sea lettuce \\
\hline J7F8P2 & 488 & 54.04 & 5.70 & -0.091 & $\begin{array}{l}\text { Laminaria japonica } \\
\text { (Sargassum japonica) }\end{array}$ & Sweet kelp \\
\hline Q32632 & 488 & 54.19 & 5.70 & -0.123 & $\begin{array}{l}\text { Mastocarpus stellatus } \\
\text { (Gigartina stellata) }\end{array}$ & $\begin{array}{l}\text { Carrageen } \\
\text { moss }\end{array}$ \\
\hline Q6X4L8 & 451 & 49.72 & 6.04 & -0.245 & $\begin{array}{l}\text { Ulva intestinalis } \\
\text { (Enteromorpha } \\
\text { intestinalis) }\end{array}$ & $\begin{array}{c}\text { Hollow green } \\
\text { nori }\end{array}$ \\
\hline Q2TVU7 & 485 & 53.77 & 5.98 & -0.122 & Gracilaria edulis & - \\
\hline Q760R7 & 488 & 53.97 & 5.80 & -0.133 & Porphyra umbilicalis & Purple laver \\
\hline H6TIB2 & 476 & 52,80 & 5.65 & -0.100 & Callophyllis variegata & Carola \\
\hline
\end{tabular}


The seaweed species were selected with respect to their high consumption. For example, Undaria pinnatifida, Sargassum fusiforme, Porphyra umbilicalis and Ulva species are commonly consumed in Asian countries as Japan being one of the leaders. On the other hand; species like Palmaria is mostly common in Western countries such as Denmark, Britain, Iceland (Mouritsen et al., 2013). The seaweed species were chosen throughout their mass consumption among the world as an oriental cuisine and novel food ingredients for vegetarian/vegan nutrition. Development of the marine ecosystem for bio-economy is an urgent topic since the idea of farming doesn't corresponds to land plants but aquatic environments are also included. Since rapid increase in the global population is a risk for food crisis; nutritious and functional food contents are motivated. With the developments in peptide-based biosciences, functional peptide-based additives are formulated for food applications as to regenerate, repair or enhance the current health status.

Bioprospecting of a bioactive peptide from mother protein source is an inconvenient and long path. Even tough existing physical treatment methods are helpful and promising for novel peptide (s) discovery, tracing back to mother protein source and predict the origin of the peptide is a challenging work when considered larger scale applications. Results of enzymatic hydrolysis of a protein depends on the choice of enzyme, operation conditions and purification methods. When a bulk protein content such as whole cells (Kose et al., 2015) are treated with enzymes, it is challenging to decipher original protein codes of the bioactive peptides unless there is not a well-defined proteome map is not available. Thus, in silico peptide prediction tools allow researchers to screen possible peptides from large protein sequence information. In silico hydrolysis and peptide bioactivity prediction has an algorithm to hydrolysis the known protein sequence to individual peptides considering the enzyme cut sequences. Also, screening comparative analysis of peptides and protein sources, identifying homology and activity is another interactive branch of peptidomics. Therefore, combining bioactive peptide prospecting using in silico design tool and databases could give rapid and reliable results and has the potential to draw a line from prediction to function.

Uniprot accession numbers along with the traditional name was presented in Table 1 . RuBisCO Large chain ( $\mathrm{RbcL}$ ) was used in this study because there were not $\mathrm{RbcS}$ sequence data for all the species. Besides, $\mathrm{RbcL}$ is majority of the protein because the activity of RuBisCO is low; large quantities of the enzyme are produced to continue cellular functionalities. The RbcL protein was in between $54-48 \mathrm{kDa}$ and there was not significant difference on their molecular masses.

Sequence alignment of RuBisCO proteins in selected seaweeds was done to see the homology in between the proteins. Cereals RuBisCo such as Oryza sativa P0C512, Hordeum vulgare P05698, Triticum aestivum $\mathrm{P} 11383$, oat Avena sativa P48684, Zea mays P00874 were also aligned with seaweeds to see their phylogenetic relations. Ulva species showed a great relativeness with cereals however the other seaweeds species were not closely related as Ulva represented (Figure 1). As in the plant RuBisCO, seaweed RuBisCO could show secondary structure homology however their primary amino acid sequence showed significant differences. The phylogeny tree confirmed their far relations. The species were diversified with their protein sequences which were an advantage to decipher more bioactive peptides. Sequence homology could give an opportunity to have an increased chance of having similar peptides in large quantities however also having diverse sequence alignments could be utilized as the possibility to have various bioactive peptides never characterized before. Since RuBisCO is an untapped source of protein (having half of the soluble proteins in plant leaves) it is advantageous to work with various types of RuBisCO origins. In this case seaweed possess a great opportunity considering aquatic mass production could be an advantage over plants however in the case of plants, there are increasing number of plant wastes which could be a starting material for RuBisCO bioactive peptides.

The total amino acid sequences were collected from Uniprot data, and amino acid distribution was investigated with Expasy Protparam tool. Amino acids with aromatic side chains showing nonpolar characteristics tend to show more antioxidant and radical scavenging activity, such as Trp, Phe, Val, Leu, Ile, Ala and Arg (Yanhong Li et al., 2008; Schurink, 2007) When amino acid composition was analyzed; it was found that Ala, Gly, Leu, Ile, Val were the major amino acids in the proteins followed by Thr, Arg, Asp, Glu, Lys (Figure 2). The amino acid distribution displayed that major contribution of amino acids were also amino acids responsible for ACE and DDP-IV inhibitory amino acids like Gly, Leu, Ile (Lafarga et al., 2014, 2016). The composition of these amino acids was as Gly (8-11\%), Leu (8-9\%), Trp (6\%), lle (4-6\%), Tyr (4-5\%). Phe (4\%) and Pro (3-4\%). The results could be concluded as the peptides derived from seaweed RuBisCO proteins could represent ACE, DPP-IV inhibitory activities along with antioxidant capacities. The bioactivity of the peptide is dependent on molecular masses, amino acid sequences, order of amino acids and structures of $\mathrm{N}$-terminal, Cterminal amino acids. For example, in the case of tyrosinase inhibitory peptides existing of at least one Arg residue in combination with $\mathrm{Val}$, Phe, Leu, Ala could be strong inhibitors for skin whitening properties (Schurink et al., 2007). Also C-terminal Tyr residue peptides containing Arg, Val, Ala, Phe, Cys also show strong binding properties for tyrosinase enzymes in various enzyme inhibition models (Abu Ubeid et al., 2009; Ochiai et al., 2016). Mostly bioactive peptides have a molecular mass less than $3 \mathrm{kDa}$ and strong candidates are smaller than 1500 Da. C-terminal amino acid residue could be critical for ACE inhibitory as well. Aromatic amino acids 


\begin{tabular}{|c|c|c|c|c|c|c|c|c|c|c|c|}
\hline Activity & A0A0R6M8Y2 & A0A220NUZ6 & Q2PQH5 & Q9THF8 & Q7Y838 & J7F8P2 & Q32632 & Q6X4L8 & Q2TVU7 & Q760R7 & H6TIB2 \\
\hline ACE Inhibitors* & 0.4734 & 0.4772 & 0.4775 & 0.4283 & 0.5034 & 0.4713 & 0.4508 & 0.5166 & 0.4536 & 0.4324 & 0.4517 \\
\hline Ubmp Activating** & 0.0205 & 0.0183 & 0.0205 & 0.0143 & 0.0180 & 0.0205 & 0.0102 & 0.0200 & 0.0144 & 0.0123 & 0.0147 \\
\hline Alpha-Glucosidase Inhibitor ${ }^{* * *}$ & 0.0020 & 0.0023 & 0.0020 & 0.0020 & 0.0045 & 0.0020 & 0.0020 & 0.0044 & 0.0041 & 0.0020 & 0.0021 \\
\hline Antiamnestic ${ }^{* * *}$ & 0.0102 & 0.0091 & 0.0102 & 0.0082 & 0.0090 & 0.0102 & 0.0082 & 0.0089 & 0.0082 & 0.0082 & 0.0084 \\
\hline Antioxidative $^{*}$ & 0.0738 & 0.0822 & 0.0799 & 0.0635 & 0.0854 & 0.0758 & 0.0656 & 0.0887 & 0.0701 & 0.0738 & 0.0714 \\
\hline Antithrombotic ${ }^{* * *}$ & 0.0102 & 0.0091 & 0.0102 & 0.0082 & 0.0090 & 0.0102 & 0.0082 & 0.0089 & 0.0082 & 0.0082 & 0.0084 \\
\hline DPP-IV Inhibitor ${ }^{*}$ & 0.6455 & 0.6484 & 0.6516 & 0.6393 & 0.6180 & 0.6496 & 0.6619 & 0.6208 & 0.6722 & 0.6537 & 0.6828 \\
\hline Hypotensive $^{* *}$ & 0.0225 & 0.0228 & 0.0246 & 0.0225 & 0.0292 & 0.0225 & 0.0205 & 0.0266 & 0.0247 & 0.0205 & 0.0210 \\
\hline Immunomodulating ${ }^{* * *}$ & 0.0041 & 0.0046 & 0.0041 & 0.0020 & 0.0045 & 0.0041 & 0.0020 & 0.0044 & 0.0021 & 0.0041 & 0.0021 \\
\hline Inhibitor ${ }^{* * *}$ & 0.0020 & 0.0023 & 0.0020 & 0.0041 & 0.0022 & 0.0020 & 0.0041 & 0.0022 & 0.0062 & 0.0041 & 0.0063 \\
\hline Neuropeptide $^{* * *}$ & 0.0082 & 0.0091 & 0.0082 & 0.0102 & 0.0045 & 0.0082 & 0.0123 & 0.0044 & 0.0062 & 0.0102 & 0.0084 \\
\hline Regulating $^{* *}$ & 0.0164 & 0.0137 & 0.0164 & 0.0102 & 0.0180 & 0.0184 & 0.0143 & 0.0022 & 0.0124 & 0.0164 & 0.0147 \\
\hline Stimulating** & 0.0328 & 0.0297 & 0.0328 & 0.0246 & 0.0337 & 0.0328 & 0.0389 & 0.0177 & 0.0330 & 0.0287 & 0.0294 \\
\hline
\end{tabular}

"Peptides having major bioactivity, ${ }^{* *}$ Peptides having mild bioactivity, ${ }^{* * *}$ Peptides having no significant activity

Table 3. A values of seaweed RuBisCO after simulated Gastric Digestion (GD), Papain and Thermolysin hydrolysis on BIOPEP

\begin{tabular}{|c|c|c|c|c|c|c|c|c|c|c|c|}
\hline Function & A0A220NUZ6 & A0A0R6M8Y2 & Q2PQH5 & Q9THF8 & Q7Y838 & J7F8P2 & Q32632 & Q6X4L8 & Q2TVU7 & Q760R7 & H6TIB2 \\
\hline \multicolumn{12}{|c|}{ Gastric Digestion (GD) } \\
\hline ACE Inhibitor & 0.0494 & 0.0485 & 0.0514 & 0.0336 & 0.0434 & 0.0494 & 0.0375 & 0.0450 & 0.0457 & 0.0415 & 0.0407 \\
\hline Antioxidative & 0.0079 & 0.0044 & 0.0059 & 0.0020 & 0.0065 & 0.0079 & 0.0040 & 0.0064 & 0.0040 & 0.0040 & 0.0061 \\
\hline Stimulating & 0.0040 & 0.0044 & 0.0040 & 0.0020 & 0.0043 & 0.0040 & 0.0020 & 0.0043 & 0.0060 & 0.0020 & 0.0061 \\
\hline DPP- IV Inhibitor & 0.0494 & 0.0441 & 0.0494 & 0.0336 & 0.0521 & 0.0474 & 0.0415 & 0.0535 & 0.0040 & 0.0395 & 0.0020 \\
\hline Renin Inhibitor & 0.0040 & 0.0044 & 0.0040 & 0.0040 & 0.0043 & 0.0040 & 0.0040 & 0.0043 & 0.0477 & 0.0040 & 0.0467 \\
\hline DPP- III Inhibitor & 0.0099 & 0.0088 & 0.0079 & 0.0119 & 0.0087 & 0.0099 & 0.0119 & 0.0086 & 0.0139 & 0.0119 & 0.0142 \\
\hline $\mathrm{DH}_{\mathrm{t}} \%$ & 36.44 & 36.20 & 36.64 & 35.25 & 35.87 & 36.24 & 36.24 & 35.84 & 36.85 & 36.44 & 36.05 \\
\hline \multicolumn{12}{|c|}{ Papain } \\
\hline Antioxidative & 0.0020 & 0.0066 & 0.0059 & 0.0040 & 0.0022 & 0.0040 & 0.0039 & 0.0021 & 0.0080 & 0.0060 & 0.0040 \\
\hline ACE Inhibitor & 0.0415 & 0.0463 & 0.0435 & 0.0514 & 0.0325 & 0.0375 & 0.0453 & 0.0300 & 0.0517 & 0.0476 & 0.0445 \\
\hline DPP- IV Inhibitor & 0.0613 & 0.0683 & 0.0593 & 0.0810 & 0.0629 & 0.0593 & 0.0748 & 0.0578 & 0.0815 & 0.0774 & 0.0850 \\
\hline Hypotensive & 0.0020 & 0.0022 & 0.0020 & 0.0020 & 0.0043 & 0.0020 & 0.0020 & 0.0043 & 0.0020 & 0.0020 & 0.0020 \\
\hline $\mathrm{DH}_{\mathrm{t}} \%$ & 40.39 & 41.06 & 40.00 & 39.80 & 42.83 & 40.20 & 38.07 & 43.13 & 40.24 & 36.96 & 38.74 \\
\hline \multicolumn{12}{|c|}{ Thermolysin } \\
\hline Antioxidative & 0.0079 & 0.0088 & 0.0079 & 0.0040 & 0.0390 & 0.0079 & 0.0040 & 0.0407 & 0.0298 & 0.0040 & 0.0040 \\
\hline ACE Inhibitor & 0.0336 & 0.0330 & 0.0336 & 0.0514 & 0.0043 & 0.0336 & 0.0316 & 0.0043 & 0.0596 & 0.0316 & 0.0324 \\
\hline DPP- IV Inhibitor & 0.0514 & 0.0617 & 0.0534 & 0.0810 & 0.0477 & 0.0514 & 0.0593 & 0.0471 & 0.0060 & 0.0593 & 0.0020 \\
\hline $\mathrm{DH}_{\mathrm{t}} \%$ & 38.82 & 39.29 & 38.62 & 37.62 & 35.00 & 38.81 & 38.42 & 36.05 & 38.25 & 38.22 & 38.54 \\
\hline
\end{tabular}




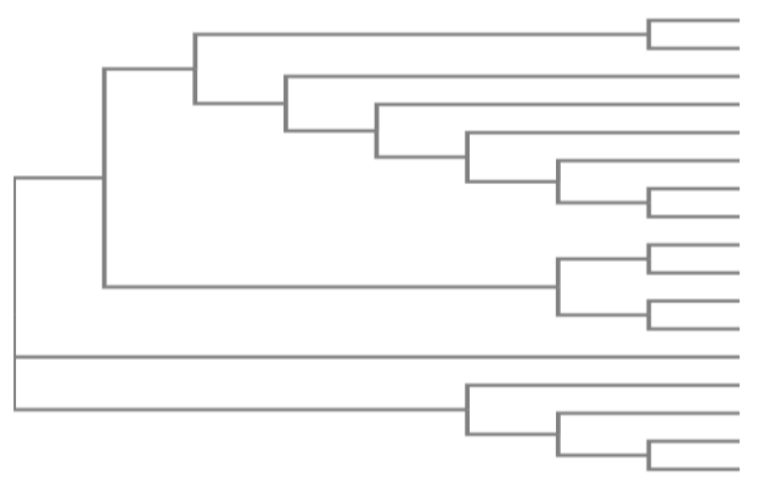

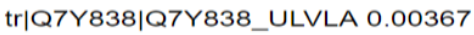
tr|Q6X4L8|Q6X4L8_ULVIN 0.00536 SP|P00875|RBL_SPIOL 0.03986 sp|P00874|RBL MAIZE 0.02439 sp|POC512|RBL_ORYSJ 0.01337 SP|P48684|RBL_AVESA 0.0094 sp|P05698|RBL_HORVU 0.00204 Sp|P11383|RBL_WHEAT O

$\operatorname{tr|AOAOR6M8Y2|AOAOR6M8Y2~UNDPI~} 0.00871$

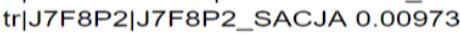

$\operatorname{tr|AOA220NUZ6|AOA220NUZ6\_ SARFS~} 0.00882$ tr|Q2PQH5|Q2PQH5_FUCVE 0.01401

SP|Q760R7|RBL_PORUM 0.04403

tr|Q9THF8|Q9THF8 PALPL 0.04322

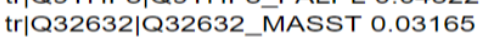

tr|Q2TVU7|Q2TVU7_9FLOR 0.02499

$\operatorname{tr|H6TIB2|H6TIB2~9FLOR~} 0.02543$

Figure 1. Multiple sequence alignment of Seaweed RuBisCO and cereals

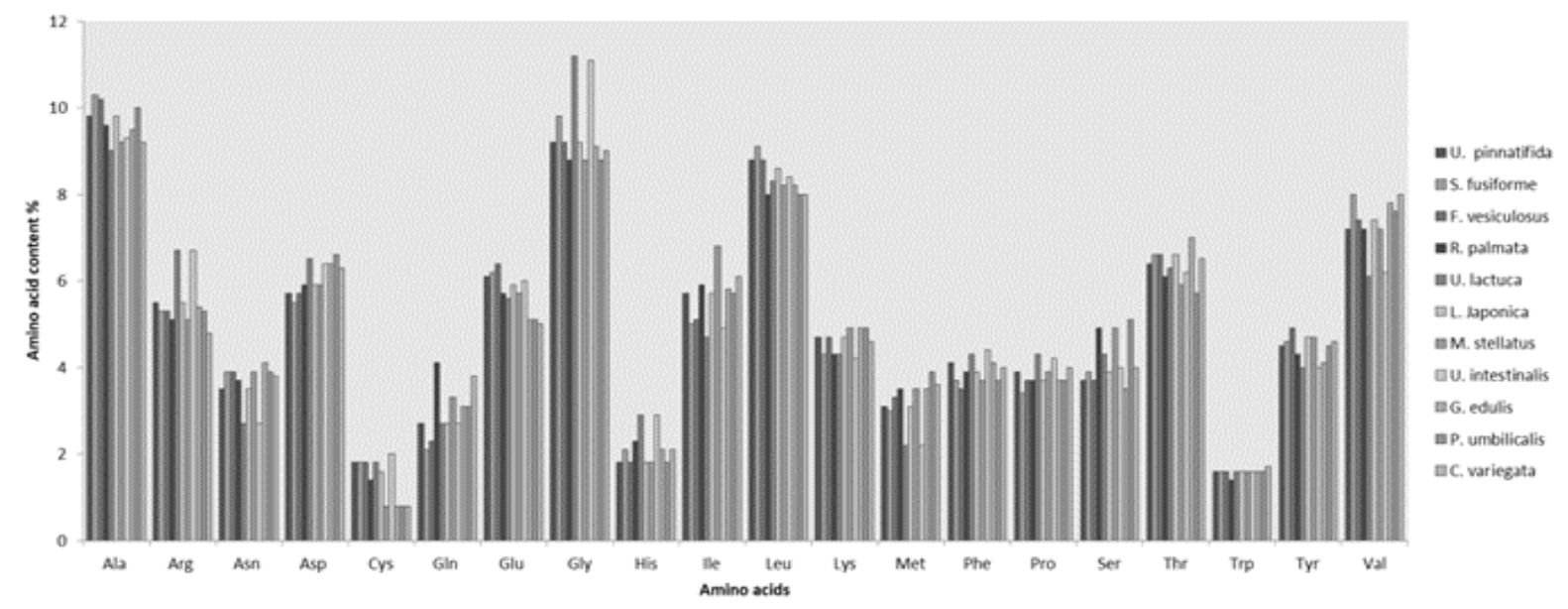

Figure 2. Amino acid sequences of seaweed RuBisCO

as Trp, Tyr and Phe and aliphatic amino acids Ile, Ala, Leu and Met give strong correlation with ACE inhibitory activity however N-terminal residue doesn't contribute significantly to the activity (J. Li et al., 2018). In the case of DPP-IV inhibitory N-terminal Trp could be responsible from the certain activity. Ile-Pro-lle analog structures could show strong inhibitory activity because Pro existence in the peptide could contribute inhibition characteristics (Liu et al., 2019). AS a result of preliminary amino acid analysis, as it was reported before, RuBisCO from seaweed also hold a great opportunity for generating various bioactive peptides.

\section{Bioactivity Prediction from Seaweed RuBisCO Proteins}

The frequency of occurrence (A) values of the proteins is highly related with the amino acid sequence of the mother protein. A values were calculated with BIOPEP database. $A=a / N$ formula represents " $a$ " as the number of bioactive peptides in the mother protein and $\mathrm{N}$ is the total amino acid residues (Minkiewicz P. et al., 2008). A value is helpful to predict the bioactivity segment of the protein and thus it is also utilized as a guide to decide which proteolytic enzyme to use to obtain peptide fragments. Prior to any enzymatic hydrolysis prediction, A values were obtained from seaweed RuBisCO proteins (Table 2). The major predicted bioactivities showed strong DPP-IV and ACE inhibition capacity. DPP-IV and ACE inhibitory activities were not significantly diverse in between the species; however, for ACE inhibitory activity $U$. intestinalis was higher with A value of 0.5166 and for DPP-IV inhibition activity C. variegate showed highest value as 0.6828 . The other potential activities could be utilized were followed as antioxidative, stimulating, UbMP activating, regulating and hypotensive. A values for other bioactivities such as antithrombotic and antiamnesic (Table 2) were so low that the attention for obtaining bioactive peptides from seaweed RuBisCO could be given for ACE inhibitory, DDP-IV inhibitory and antioxidant activities. The results are in a good accordance with the literature and demand in the bioactive ingredient industry (Selvaraj et al., 2017; Udenigwe et al., 2017a).

\section{In Silico Enzymatic Hydrolysis}

BIOPEP web server has an "Enzyme(s)" action to simulate proteolysis by endopeptidases introduced in the database. By choosing the enzyme of interest, a protein sequence can be hydrolyzed into peptide products. The system allows to hydrolyze the proteins 


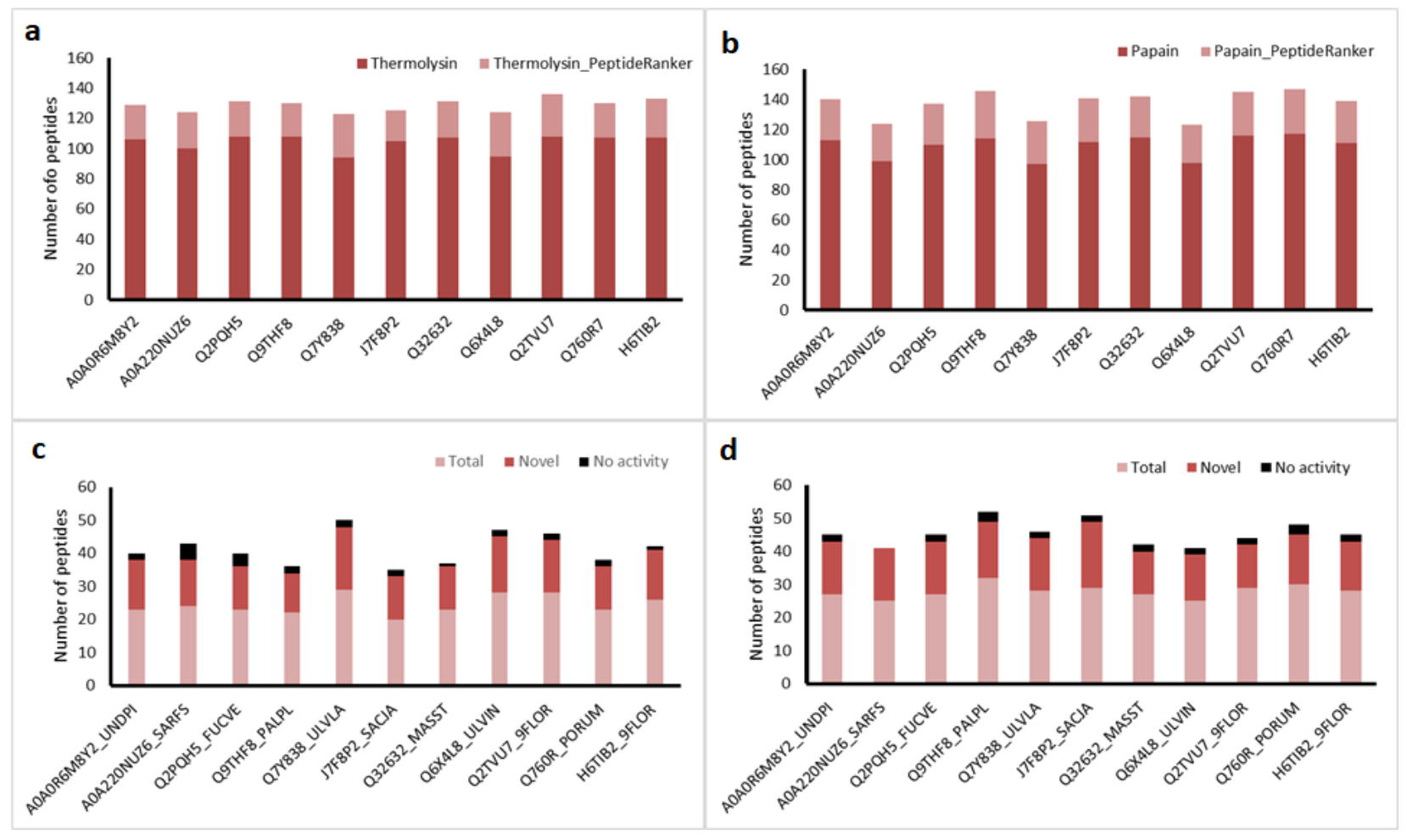

Figure 3. Number of peptides released from a) thermolysin, b) papain hydrolysis, number of peptides having Peptide Ranker score higher than 0.5 for $\mathrm{c}$ ) thermolysin, d) papain.

with three enzymes simultaneously. This is beneficial to simulate gastric digestion profiles. In this study, Thermolysin and papain enzymes were selected. The seaweed RuBisCO proteins were digested in silico by thermolysin and papain using BioPEP. The both enzymes are conventional food processing enzymes and could give a strong contribution for the development of predicted bioactive peptides. These enzymes also give peptides 2-50 amino acid chains which increase possibility to find short sequence low molecular weight bioactive peptides. The A values showed that both enzymes give mostly DPP-IV and ACE inhibitory peptides followed by antioxidative properties (Table 3). Some hypotensive and neuropeptide scores could be observed however, due to low A values, these bioactivities could be neglected. Regardless from the enzyme, di- and tri-peptides were released from mother proteins for each seaweed species. More than 600 peptides could be observed. Because seaweed species share common conserved sequences, the digestion results gave almost the same dipeptides.

The digested peptides were evaluated on PeptideRanker to find the possible peptides with certain bioactivities. 0.5 in PeptideRanker was taken as threshold and number of the peptides in Thermolysin and Papain were calculated (Figure 3). For thermolysin 69 possible bioactive peptide was calculated including dipeptides and decapeptides. 81 different peptides were identified with papain digestion. 11 of these peptides were obtained both papain and thermolysin digestion. Seven of these peptides were identified with ACE and/or DPP-IV inhibitor activities in BIOPEP database; MR (DPP-IV inhibitor), VW (ACE, DDP-IV inhibitor, antioxidant, glucose uptake inhibitor), IPG (ACE inhibitor), APG (DPP-IV inhibitor), AG (DDP-IV and ACE inhibitor), YR (DPP-IV inhibitor) and IG (ACE inhibitor). On the other hand, even though the PeptideRanker score was under 0.5; some dipeptides with ACE and DPP-IV inhibitory activities could be identified from thermolysin and papain digestion. The resulting peptides possess some bioactivities and deciphering them could be another topic of mining bioactive peptide from natural sources.

\section{Simulated GI Digestion}

Simulated Gl digestion for seaweed RuBisCO proteins was done to understand the occurrence of cryptic bioactive peptides in digestive tract. One of the major sources of observing bioactive peptides is the $\mathrm{GI}$ digestion. Naturally, when humans and animals consume protein sources, proteinaceous materials meet with $\mathrm{Gl}$ enzymes such as amylase, lipases, pepsin, trypsin, and chymotrypsin. Direct consuming of protein rich foods is the major and cheaper way to obtain bioactive peptides and predict their beneficial effects rather than taking specially designed peptide formulations unless it is not recommended for health practitioners for people in need. For this purpose, BIOPEP enzymes action tool was utilized for GI simulation. Each protein is digested in silico with pepsin (pH > 1.3), trypsin (EC 3.4.21.4) and chymotrypsin (EC3.4.21.1). 


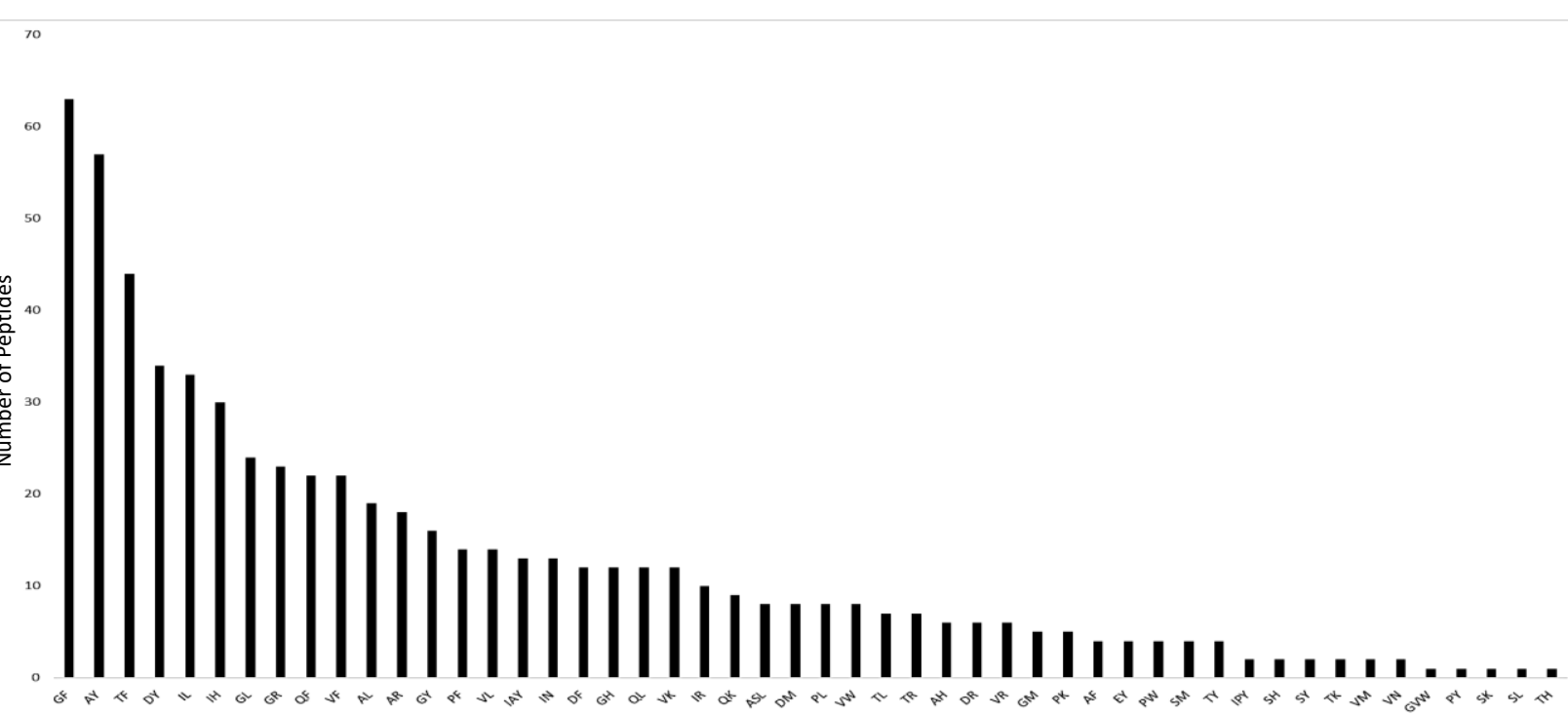

Figure 4. Number of relased bioactive peptides and their sequences in seaweed RuBisCO proteins.

Gl digestion simulation resulted that when these proteins are consumed as food supplement, they are more susceptible as ACE inhibitory and DDP-IV inhibitory activities followed by antioxidant capacity (Table 3). Digestion resulted on mostly dipeptides and several tripeptides. Number of obtained peptides for each protein was approximately 30 and most of them already existed in the peptide database from several sources. From overall gastric digestion of seaweed RuBisCO, 50 different di- and tripeptides were found with primary activity of ACE and DPP-IV inhibitory followed by DPP-III inhibition and antioxidant effect. GF, $\mathrm{AY}, \mathrm{IH}, \mathrm{IL}, \mathrm{TF}$ occurred more than 30 times due to the rich composition of seaweed proteins in terms of Gly, Phe, Ala and lle amino acids which mostly give antioxidant, ACE ad DPP-IV inhibitory activities to the peptides (Figure 4). Peptides like VF, YL, FY, AF, VR,SY,KY, AR, TF, $I A Y, A Y, A S L, I L, I P Y, I H$ and IPY with IC 50 values less than $300 \mu \mathrm{M}$ (Chang \& Alli, 2012) peptides were abundant also in seaweed peptides when compared to food sources like legumes, grains, meat and dairy products.

Inhibition of DPP-IV enzyme is new type of therapeutic approach on the treatment of type 2 Diabetes mellitus (Deng et al., 2018). Peptides such as TF, GF, IPY, AY with multiple bioactivities is advantage considering gastric digestion could help releasing peptides with multifunctionalities. ACE inhibitors function as ACE receptor blockers, usually people having hypertension use drugs containing ACE inhibitors. ACE inhibitor molecules are also important due to strong relation of cardiovascular diseases with hypertension problems. The demand on natural peptides with ACE inhibitory activities are increasing, firstly peptides could be derived from food sources naturally and by a regular diet. This study showed that, seaweeds holds a great opportunity for dietary ACE and DPP-IV inhibitory peptides as results observed by simulated GI digestion. The limitation here could be the second digestion of an oligopeptide when consumed by diet, however hence we showed most of the ACE and DPP-IV inhibitory peptides are di- and tripeptides having a low chance to digested by GI tract.

\section{Opioid Peptides}

Food derived peptides, and proteins have cryptic opioid peptides with some analgesic and anxiolytic effect. Milk and wheat derived peptides were known to have some opioid properties, however; RuBisCO large subunit of spinach gave 2 new opioid peptides binding the $D 1$ receptor, activating $\sigma 1$ to show some anxiolytic effects (Hirata et al., 2007). These opioid peptides also helped impairing cognitive behavior in mice. Rubiscolin6 was also found to be a stimulating peptide for food intake in mice model. The rubiscolin-5 (YPLDL) and rubiscolin-6 (YPLDLF) were found in Ulva lactuca and Ulva intestinalis. The other seaweed RuBisCO proteins were not having rubiscolins in their mother amino acid sequence. When $U$. lactuca and $U$. intestinalis RuBisCO was BLAST, the sequence similarity was found to be 88$98 \%$ in most of the microalgae species which are biotechnologically important such as Chlorella sp., Chlorella vulgaris, Chlorella elipsoidea, Dunaliella, Ostreococcus tauri, and rubiscolins were conserved. We blast $U$. lactuca and $U$. intestinalis RuBisCO against Spinach RuBisCO large chain and found $86.07 \%$ and $86.86 \%$ sequence similarities, respectively. Especially the sequences of 15 amino acids which embedded rubiscolin peptides were highly conserved when compared to spinach. According to in-silico digest, there was no enzyme cutting the exact sequence of rubiscolin$5 / 6$ however, some of the enzymes cut rubiscolins in specific locations to give other bioactive fragments. The abundant portion was an ACE inhibitory peptide IAY $\left(I C_{50}=12.59 \mu \mathrm{M}\right)$ and obtained by enzymes such as chymotrypsin $A / C$, chymase, ficin, metridin, subtisilin and cathepsin G. ACE and DDP-IV inhibitory peptide PL $\left(\mathrm{IC}_{50}=337.32 \mu \mathrm{M}\right)$ was obtained by gastric enzymes, 
papain, ficin, subtisilin, chymase, metridin, bromelain, calpain 2, cathepsin G, leukocyte elastase, oligopeptidase F. Another bioactive dipeptide was YP (ACE inhibitory IC50=720 $\mu \mathrm{M}$; DPP-IV inhibitory $I C 50=3170 \mu \mathrm{M})$. Yang et al. showed the pepsin digestion of spinach natural RuBisCO and synthetic peptide sequence (ICYVAYPLDLFEEG) where rubiscolins exist. In Ulva species, Rubiscolin sequences are conserved but $\mathrm{V}$ is replaced with I and C was replaced with $A$. When simulated pepsin digestion was done, it was susceptible that -AYPLDL- sequence can be released depending on the enzymatic hydrolysis conditions (Udenigwe et al., 2017a). This gives the idea that oral administration of Ulva species could result as the intake of opioid rubiscolins. The concentration of the rubiscolin is however dependent on the degree of hydrolysis, intake in GI tract and total consumption of Ulva biomass on daily basis. When rubiscolin oral administration was done to mice, the activity of the peptide was considered as a critical point for the receptor-ligand interactions to signal increasing food intake (Kaneko et al., 2012).

\section{Anti-Inflammatory (AI) Peptide Prediction}

Anti-inflammatory responses of host organism are a strong and complex defense systems to fight against pathogens and unwanted substances. Development of novel anti-inflammatory molecules is urgent for curing auto-immune and inflammatory chronic diseases (Yuan et al., 2016). Synthetic and natural compounds could have certain Al activity. Recently peptides derived from food, marine and fungal organisms also venom of spiders, snakes and some other arthropods are susceptible sources for natural treatment of chronic and acute inflammation. When an inflammation stimulus is observed cellular signaling molecules as cytokines of the interleukin (IL) families, tumor necrosis factor alpha (TNF- $\alpha$ ), prostaglandins (PG), nitric oxide (NO), and leukotrienes (LTs) are released from cells. Also, enzymes such as nitric oxide synthase (iNOS) and protein kinase $C$ (PKC) are crucial for response generation. In this part of the study, peptides derived from gastric digestion, papain and thermolysis hydrolysis which also show a score higher than 0.5 in Peptide Ranker was utilized for Al peptide prediction (Dadar et al., 2019).

Among 80 peptides with various lengths of amino acids we found 24 peptides susceptible of Al activity. Scoring of the peptides probable activity was done according to the prediction server. However, peptides giving score under 0.2 were negative and score between 0.3-0.4 show low probability, 0.4-0.5 show medium probability and 0.5 - to higher show higher probability of Al activity. In general, peptides having 5 or more amino acid sequences gave also increasing probability of $\mathrm{Al}$ activity. In this case, we found 4 peptides ACDIYR (0.549), QDWVSL (0.549), SVICMIDL (0.545), VICKWMR (0.527). 5 of peptides showed medium Al activity and the rest was predicted to show low Al activity (Table 4). According to the observations both Peptide Ranker and Al databases, the base sequence DMIL looks interesting for the meaning of Al activity. Peptides generated from DMIL such as HDMIL and NDMIL also susceptible from

Table 4. In silico Anti-inflamatory peptide prediction

\begin{tabular}{|c|c|c|c|c|}
\hline $\begin{array}{l}\text { Peptide } \\
\text { Sequence }\end{array}$ & $\begin{array}{l}\text { Peptide Ranker } \\
\text { Score }\end{array}$ & $\begin{array}{l}\text { Combined RF score } \\
\text { (probability) }\end{array}$ & Allergenity & $\begin{array}{l}\text { Tanimoto similarity index with protein in } \\
\text { database }\end{array}$ \\
\hline ACDIYR & 0.64966 & 0.549 & Yes & 0.78 / NCBI gi number 51316200 \\
\hline QDWVSL & 0.491286 & 0.549 & Yes & 0.81/ NCBI gi number 30908930 \\
\hline SVICMIDL & 0.513388 & 0.545 & Yes & 0.77/ NCBI gi number 30908930 \\
\hline VICKWMR & 0.807916 & 0.527 & No & 0.74/UniProtKB accession number P80813 \\
\hline YCMEG & 0.54467 & 0.514 & Yes & $0.83 /$ NCBI gi number 51316200 \\
\hline CYDIEPL & 0.555929 & 0.451 & Yes & 0.72/ NCBI gi number 30908930 \\
\hline IHVWHMP & 0.677358 & 0.437 & Yes & 0.75/ NCBI gi number 30908930 \\
\hline IHCG & 0.550607 & 0.429 & Yes & $0.82 / N C B I$ gi number 51316200 \\
\hline WKDISF & 0.715281 & 0.421 & Yes & 0.79/ NCBI gi number 51316200 \\
\hline ACKWSPEL & 0.713336 & 0.406 & No & $0.70 /$ UniProtKB accession number Q7M1U4 \\
\hline ACKWSP & 0.679043 & 0.384 & Yes & $0.75 /$ NCBI gi number 30908930 \\
\hline DPVMI & 0.505963 & 0.379 & No & 0.83/ UniProtKB accession number P80820 \\
\hline KNDMIL & 0.519663 & 0.376 & Yes & 0.83/ NCBI gi number 30908930 \\
\hline AIWSR & 0.624844 & 0.367 & Yes & 0.85/ NCBI gi number 51316200 \\
\hline LYYL & 0.593875 & 0.363 & Yes & 0.83/ NCBI gi number 51316200 \\
\hline MDKF & 0.8092 & 0.354 & Yes & 0.83/ NCBI gi number 51316200 \\
\hline YWDPEHVIL & 0.49981 & 0.353 & Yes & 0.71/ NCBI gi number 25090949 \\
\hline HDMIL & 0.616997 & 0.352 & No & 0.83 / UniProtKB accession number P80820 \\
\hline DMDW & 0.860391 & 0.348 & No & 0.82/ UniProtKB accession number P80820 \\
\hline DMIL & 0.606999 & 0.346 & No & 0.83 / UniProtKB accession number P80820 \\
\hline QPYL & 0.685675 & 0.345 & Yes & 0.82/ NCBI gi number 51316200 \\
\hline NDMIL & 0.605273 & 0.331 & No & $0.81 /$ UniProtKB accession number $\mathrm{P} 80820$ \\
\hline ACDL & 0.620836 & 0.325 & No & $0.83 /$ UniProtKB accession number $\mathrm{P} 80820$ \\
\hline YYL & 0.598987 & 0.319 & No & 0.83/UniProtKB \# Q8IZT6 \\
\hline
\end{tabular}

* Probability scores for AIP prediction ( $>0.5$, high; $0.5<\mathrm{P}<0.4$, medium; $<0.3$ low) 
certain Al activities. L, Y, S, R and E in N-terminal flanking of peptides were susceptible for Al activity in RuBisCO hydrolysates, all the peptides having medium and high activity has one of these amino acids in their $\mathrm{N}$ terminal sides. Also, $\mathrm{L}, \mathrm{Q}, \mathrm{S}$ and $\mathrm{R}$ at $\mathrm{C}$ terminal side give high probability of $\mathrm{Al}$ activity. The peptides with high $\mathrm{Al}$ prediction show $\mathrm{C}$ terminal and $\mathrm{N}$ terminal conserved amino acid sequences in the case of ACDIYR and QDWVSL, SVICMILD. Sequences such as $C$ terminal $P, G$ and $A$ and $N$ terminal $A, G, V, P$ and $N$ decreases the probability (Gupta et al., 2017). Peptides showing probability less than 0.4 has these amino acid sequences in their $\mathrm{N}$ and $\mathrm{C}$ terminal sides. Seaweed RuBisCO derived Al peptides are promising candidates for novel food derived Al-peptides. Thus, further in vitro and in vivo activity screening of RuBisCO derived $\mathrm{Al}$ peptides are required.

\section{Toxic Peptide Prediction}

The recent therapeutic approaches are moving towards to peptide/protein-based therapies. Rather than having synthetic analogs, enzymatic hydrolysates rich in susceptible bioactive peptides is one of the main topics in peptide-based therapeutics research. However, peptides still have some concerns on stability, activity, immunogenicity, and toxicity. Cytotoxic effects are mostly examined using in vitro animal cell cultures. However, when protein hydrolysates are in the case certain chromatographic purification steps should be adapted to see the active/toxic peptide(s) inside the hydrolysates cocktail. In this study an in-silico toxin prediction tool, ToxinPred, was adapted to mine toxic sequences inside seaweed RuBisCO proteins. The mother protein sequences were digested in silico using BIOPEP enzymes tool to decipher the enzymes responsible for the release of certain toxic peptides. 13 different peptide sequences were found in 11 RuBisCO enzymes. S. fusiforme, $M$. stellatus, $C$. edulis and $C$. variegate species didn't give any toxic peptides. $P$. palmata had 8 different peptides susceptible from toxicity. Table 5 gives probable toxic peptides derived from seaweed species. The table also shows the release of peptide when digested certain proteolytic enzymes. It is known that peptides containing Cys, His, Asn, Pro have a higher tendency to be toxic (Gupta et al., 2013). Peptides predicted to be o be toxic contains at least one Cys residue except AKMGYWDADY which is released from four different seaweed species. However, another study find that peptides rich in Pro didn't give significant toxic effect (Lafarga et al., 2014). It is considered as not to be a rule of thumb however susceptibility is increasing. The proteolytic degradation properties were analyzed, and enzymes releasing toxic peptides were identified (Table 5). Gastrointestinal enzymes such as pepsin and some commercial proteases such as subtisilin, proteinase $\mathrm{K}, \mathrm{V}-8$ protease could release the toxic peptides. It could be noted that gastric digestion of these seaweed species could give some toxic peptides released to $\mathrm{Gl}$ tract however their toxicity should be investigated in vitro and in vivo experiments via designing synthetic peptides and purification via enzymatic hydrolysis of bulk protein.

From toxic peptides obtained from ToxinPred database results, anticancer properties of the peptides were also analyzed using iACP, AntiCP, MLACP in silico anticancer peptide prediction tools. The results given by each tool gave some different results. All the databases agreed on the anticancer possibility of P4, P5 and P9 and non-anticancer properties of $\mathrm{P} 13$. According to antiCP all the peptides except $\mathrm{P} 13$ could show anticancer activity. iACP suggested that P4-P8 and P9-10 could be anticancer and MLAPC suggested P2-P5 and P9 could show some anticancer activity. SWM score for common anticancer peptide P9 was the highest (1.32 for AntiCP). These peptides could be candidates for certain anticancer activity however the verification of in silico results should be done to see the actual effect in vitro and if so, continue for in vivo experiments.

The in-silico bioactivity prediction tools are helpful to choose the starting point when dealing with mining and bioprospecting approach for the development of natural therapeutics. In this study, RubisCO protein hydrolysates from seaweed species showed that macroalgae was strong candidates for the development of ACE, DPP-IV inhibitory peptides and some additional bioactivities as anticancer and antioxidant properties. The peptides were predicted via in silico enzymatic hydrolysis web server rather than designing in vitro experiments. By this method, the time and experimental design for actual hydrolysis were decreased. However, it should be kept in mind that, one of the limitation of this method $s$ the requirement of known protein sequences. On the other hand, when these sequences are known the method is simple and effective. The activity of the possibly released peptides could be achieved with the verification of designing synthetic peptides of the predicted ones and also recombinant bulk production of the relevant peptide could be an option to develop the industrial aspects of the natural bioactive peptides. In vitro and in vivo activity models, in vitro digestion examination will help the verification of the peptides and validated by various wet-lab techniques.

\section{Conclusion}

Seaweed RuBisCO proteins could be promising source for development of DPP-IV, ACE inhibitors and antioxidant activities. According to our results, most of the strong peptide inhibitors $\left(\mathrm{IC}_{50}<300 \mu \mathrm{M}\right)$ for DDP-IV and ACE obtained in dairy and meat sources could be achieved from seaweed species, too. RuBisCO papain and, thermolysin hydrolysates are novel sources of antiinflammatory peptides as well. Consuming seaweed products could be one of the functional food substitutes for individuals preferring vegetarian and vegan nutrition. However, verification and actualization of the toxicity and bioactivity of the peptides could be done to 
Table 5. Toxic peptide prediction and list of proteases releasing toxic sequence

\begin{tabular}{|c|c|c|c|c|c|c|}
\hline Species & $\begin{array}{l}\text { Peptide } \\
\text { code }\end{array}$ & $\begin{array}{l}\text { Toxic peptide } \\
\text { sequence }\end{array}$ & $\begin{array}{l}\text { SWM } \\
\text { Score }\end{array}$ & Digestive enzyme & Allergen & \\
\hline \multirow{8}{*}{$\begin{array}{l}\text { P. palmata } \\
\text { (Q9THF8) }\end{array}$} & P1 & TACDLYRAKC & 0.13 & - & No & $\begin{array}{c}\text { 0.66/UniProtKB accession number } \\
\text { P80814 }\end{array}$ \\
\hline & $\mathrm{P} 2$ & ACDLYRAKCY & 0.53 & - & Yes & 0.69/ NCBI gi number 280371 \\
\hline & P3 & CDLYRAKCYK & 0.48 & - & Yes & $\begin{array}{c}\text { 0.66/UniProtKB accession number } \\
\text { P01153 }\end{array}$ \\
\hline & P4 & DLYRAKCYKV & 0.21 & - & No & $\begin{array}{c}\text { 0.67/UniProtKB accession number } \\
\text { Q7M1S9 }\end{array}$ \\
\hline & P5 & LYRAKCYKVD & 0.32 & V-8 protease & Yes & $0.68 / \mathrm{NCBI}$ gi number 54036219 \\
\hline & P6 & YRAKCYKVDA & 0.18 & $\begin{array}{c}\text { Pepsin } \\
\text { Pancreatic elastase } \\
\text { II } \\
\text { Oligopeptidase F }\end{array}$ & Yes & $0.69 / \mathrm{NCB}$ gi number 248058 \\
\hline & P7 & RAKCYKVDAV & 0.16 & - & Yes & $0.65 /$ NCBI gi number 46396597 \\
\hline & P8 & AKCYKVDAVP & 0.17 & $\begin{array}{c}\text { Clostripain } \\
\text { Prolyl } \\
\text { oligopeptidase }\end{array}$ & No & $\begin{array}{l}\text { 0.67/UniProtKB accession number } \\
\text { P80810 }\end{array}$ \\
\hline \multirow[t]{2}{*}{$\begin{array}{l}\text { U. lactuca } \\
\text { (Q7Y838) } \\
{ }^{*} \text { U. intestinalis } \\
\text { (Q6X4L8) }\end{array}$} & P9 & DRYKGRCYDI* & 0.06 & $\begin{array}{c}\text { Pepsin } \\
\text { Pancreatic elastase } \\
\text { II } \\
\text { Leukocyte elastase } \\
\text { Oligopeptidase F } \\
\text { Lactocepin }\end{array}$ & Yes & 0.68/NCBI gi number 25090949 \\
\hline & P10 & RYKGRCYDIE* & 0.21 & $\begin{array}{l}\text { Proteinase } \mathrm{K} \\
\mathrm{V}-8 \text { protease }\end{array}$ & No & $\begin{array}{c}\text { 0.63/UniProtKB accession number } \\
\text { P80814 }\end{array}$ \\
\hline $\begin{array}{l}\text { U. pinnatifida } \\
\text { (A0A0R6M8Y2) } \\
\text { F. vesiculosus (Q2PQH5) } \\
\text { S. japonica } \\
\text { (J7F8P2) } \\
\text { P. umbilicalis } \\
\text { (Q760R7) }\end{array}$ & P11 & AKMGYWDADY & 0.06 & - & No & $\begin{array}{c}\text { 0.71/UniProtKB accession number } \\
\text { Q7M1G2 }\end{array}$ \\
\hline \multirow[t]{2}{*}{$\begin{array}{l}\text { U. intestinalis } \\
(\mathrm{Q} 6 \mathrm{X} 4 \mathrm{~L} 8)\end{array}$} & P12 & NATAGTCEEM & 0.01 & $\begin{array}{c}\text { Pepsin } \\
\text { Proteinase K } \\
\text { Cathepsin G } \\
\text { Metridin } \\
\text { Pancreatic elastase } \\
\text { Subtilisilin } \\
\text { Oligopeptidase F } \\
\text { Lactocepin } \\
\end{array}$ & Yes & 0.68/NCBI gi number 54036219 \\
\hline & P13 & GDDACLQFGG & 0.03 & - & No & $\begin{array}{c}\text { 0.71/UniProtKB accession number } \\
\text { Q8IZT6 }\end{array}$ \\
\hline
\end{tabular}

develop novel formulas. Challenges as cost, public preference, contribution to nature and natural sources, circular economy of the processes should be considered.

\section{Ethical Statement}

Ethical statement is not required.

\section{Funding Information}

Authors does not decleare any funding information.

\section{Author Contribution}

The author designed and did the analysis. The manuscript is written and edited by the author.

\section{Conflict of Interest}

The author(s) declare that they have no known competing financial or non-financial, professional, or personal conflicts that could have appeared to influence the work reported in this paper."

\section{References}

Abu Ubeid, A., Zhao, L., Wang, Y. \& Hantash, B.M. (2009). Short-sequence oligopeptides with inhibitory activity against mushroom and human tyrosinase. Journal of Investigative Dermatology, 129(9), 22422249.

https://doi.org/10.1038/jid.2009.124

Agyei, D., Tsopmo, A. \& Udenigwe, C.C. (2018). Bioinformatics and peptidomics approaches to the discovery and analysis of foodderived bioactive peptides. Analytical and Bioanalytical Chemistry, 410(15), 3463-3472.

https://doi.org/10.1007/s00216-018-0974-1

Chang, Y.W. \& Alli, I. (2012). In silico assessment: Suggested homology of chickpea (Cicer arietinum L.) legumin and prediction of ACEinhibitory peptides from chickpea proteins using BLAST and BIOPEP analyses. Food Research International, 49(1), 477-486. https://doi.org/10.1016/j.foodres.2012.07.006

Chen, W., Ding, H., Feng, P., Lin, H. \& Chou, K.C. (2016). iACP: A sequencebased tool for identifying anticancer peptides. Oncotarget, $7(13)$ 16895-16909.

https://doi.org/10.18632/oncotarget.7815

Dadar, M., Shahali, Y., Chakraborty, S., Prasad, M., Tahoori, F., Tiwari, R. \& Dhama, K. (2019). Antiinflammatory peptides: current knowledge and promising prospects. Inflammation Research, 68(2), 125-145. https://doi.org/10.1007/s00011-018-1208-x

Deng, Z., Liu, Y., Wang, J., Wu, S., Geng, L., Sui, Z. \& Zhang, Q. (2018). Antihypertensive effects of two novel angiotensin i-converting enzyme (ace) inhibitory peptides from gracilariopsis lemaneiformis (Rhodophyta) in spontaneously hypertensive rats (SHRs). Marine Drugs, 16(9). 
https://doi.org/10.3390/md16090299

Fan, X., Bai, L., Zhu, L., Yang, L. \& Zhang, X. (2014). Marine algae-derived bioactive peptides for human nutrition and health. Journal of Agricultural and Food Chemistry, 62(38), 9211-9222. https://doi.org/10.1021/jf502420h

FitzGerald, R.J., Cermeño, M., Khalesi, M., Kleekayai, T. \& Amigo-Benavent, M. (2019). Application of in silico approaches for the generation of milk protein-derived bioactive peptides. Journal of Functional Foods, 103636. https://doi.org/10.1016/J.JFF.2019.103636

Gu, Y., Majumder, K. \& Wu, J. (2011). QSAR-aided in silico approach in evaluation of food proteins as precursors of ACE inhibitory peptides. Food Research International, 44(8), 2465-2474. https://doi.org/10.1016/j.foodres.2011.01.051

Gupta, S., Kapoor, P., Chaudhary, K., Gautam, A., Kumar, R. \& Raghava, G. P.S. (2013). In Silico Approach for Predicting Toxicity of Peptides and Proteins. PLOS ONE, 8(9). https://doi.org/10.1371/journal.pone.0073957

Gupta, S., Sharma, A.K., Shastri, V., Madhu, M.K. \& Sharma, V.K. (2017). Prediction of anti-inflammatory proteins/peptides: An insilico approach. Journal of Translational Medicine, 15(1), 1-11. https://doi.org/10.1186/s12967-016-1103-6

Hirata, H., Sonoda, S., Agui, S., Yoshida, M., Ohinata, K. \& Yoshikawa, M. (2007). Rubiscolin-6, a $\delta$ opioid peptide derived from spinach Rubisco, has anxiolytic effect via activating $\sigma 1$ and dopamine D1 receptors. Peptides, 28(10), 1998-2003. https://doi.org/10.1016/J.PEPTIDES.2007.07.024

Kaneko, K., Lazarus, M., Miyamoto, C., Oishi, Y., Nagata, N., Yang, S., Yoshikawa, M., Aritake, K., Furuyashiki, T., Narumiya, S., Urade, Y. \& Ohinata, K. (2012). Orally administered rubiscolin-6, a $\delta$ opioid peptide derived from Rubisco, stimulates food intake via leptomeningeal lipocallin-type prostaglandin $D$ synthase in mice. Molecular Nutrition and Food Research, 56(8), 1315-1323. https://doi.org/10.1002/mnfr.201200155

Kose, A. \& Oncel, S.S. (2015a). Properties of microalgal enzymatic protein hydrolysates: Biochemical composition, protein distribution and FTIR characteristics. Biotechnology Reports, 6, 137-143. https://doi.org/10.1016/j.btre.2015.02.005

Kose, A. \& Oncel, S.S. (2015b). Properties of microalgal enzymatic protein hydrolysates: Biochemical composition, protein distribution and FTIR characteristics. Biotechnology Reports, 6, 137-143. https://doi.org/10.1016/J.BTRE.2015.02.005

Lafarga, T., O'Connor, P. \& Hayes, M. (2014). Identification of novel dipeptidyl peptidase-IV and angiotensin-I- converting enzyme inhibitory peptides from meat proteins using in silico analysis. Peptides, 59, 53-62. https://doi.org/10.1016/j.peptides.2014.07.005

Lafarga, T., O'Connor, P. \& Hayes, M. (2015). In silico methods to identify meat-derived prolyl endopeptidase inhibitors. Food Chemistry, 175, 337-343. https://doi.org/10.1016/j.foodchem.2014.11.150

Lafarga, T., Wilm, M., Wynne, K. \& Hayes, M. (2016). Bioactive hydrolysates from bovine blood globulins: Generation, characterisation, and in silico prediction of toxicity and allergenicity. Journal of Functional Foods, 24, 142-155. https://doi.org/10.1016/j.jff.2016.03.031

Li, J., Liu, Z., Zhao, Y., Zhu, X., Yu, R., Dong, S. \& Wu, H. (2018). Novel natural angiotensin converting enzyme (ACE)-inhibitory peptides derived from sea cucumber-modified hydrolysates by adding exogenous proline and a study of their structure $\Downarrow$ activity relationship. Marine Drugs, 16(8). https://doi.org/10.3390/md16080271

Li, Yanhong, Jiang, B., Zhang, T., Mu, W. \& Liu, J. (2008). Antioxidant and free radical-scavenging activities of chickpea protein hydrolysate (CPH). Food Chemistry, 106(2), 444-450. https://doi.org/10.1016/j.foodchem.2007.04.067

Li, Yunliang, Wang, B., Zhang, H., Wang, Z., Zhu, S. \& Ma, H. (2015). Highlevel expression of angiotensin converting enzyme inhibitory peptide Tuna Al as tandem multimer in Escherichia coli BL21 (DE3). Process Biochemistry, 50(4), 545-552. https://doi.org/10.1016/j.procbio.2015.01.017

Liang, R., Zhang, M.S. \& Lin, S.Y. (2014). Recombinant Expression of Bioactive Peptides: A Review. Advanced Materials Research, 881$883,331-334$.

https://doi.org/10.4028/www.scientific.net/amr.881-883.331

Liu, R., Cheng, J. \& Wu, H. (2019). Discovery of food-derived dipeptidyl peptidase IV inhibitory peptides: A review. International Journal of
Molecular Sciences, 20(3). https://doi.org/10.3390/ijms20030463

Morris, H.J., Almarales, A., Carrillo, O. \& Bermúdez, R. C. (2008). Utilisation of Chlorella vulgaris cell biomass for the production of enzymatic protein hydrolysates. Bioresource Technology, 99(16), 7723-7729. https://doi.org/10.1016/j.biortech.2008.01.080

Mouritsen, O.G., Dawczynski, C., Duelund, L., Jahreis, G., Vetter, W. \& Schröder, M. (2013). On the human consumption of the red seaweed dulse (Palmaria palmata (L.) Weber \& Mohr). Journal of Applied Phycology, 25(6), 1777-1791. https://doi.org/10.1007/s10811-013-0014-7

Nongonierma, A.B. \& Fitzgerald, R.J. (2014). An in silico model to predict the potential of dietary proteins as sources of dipeptidyl peptidase IV (DPP-IV) inhibitory peptides. Food Chemistry, 165, 489-498. https://doi.org/10.1016/j.foodchem.2014.05.090

Ochiai, A., Tanaka, S., Imai, Y., Yoshida, H., Kanaoka, T., Tanaka, T. \& Taniguchi, M. (2016). New tyrosinase inhibitory decapeptide: Molecular insights into the role of tyrosine residues. Journal of Bioscience and Bioengineering, 121(6), 607-613. https://doi.org/10.1016/j.jbiosc.2015.10.010

Onuh, J.O., Girgih, A.T., Aluko, R.E. \& Aliani, M. (2014). In vitro antioxidant properties of chicken skin enzymatic protein hydrolysates and membrane fractions. Food Chemistry, 150, 366-373. https://doi.org/10.1016/j.foodchem.2013.10.107

Schurink, M. (2007). Peptides as inhibitors of lipoxygenase and tyrosinase. In Chemistry (Vol. 58). https://doi.org/978-90-8504-845-9

Schurink, M., van Berkel, W.J.H., Wichers, H.J. \& Boeriu, C.G. (2007). Novel peptides with tyrosinase inhibitory activity. Peptides, 28(3), 485495. https://doi.org/10.1016/j.peptides.2006.11.023

Selvaraj, G., Kaliamurthi, S., Cakmak, Z.E. \& Cakmak, T. (2017). Research article RuBisCO of microalgae as potential targets for nutraceutical peptides: A computational study. Biotechnology, 16(4-6), 130-144. https://doi.org/10.3923/biotech.2017.130.144

Tejano, L.A., Peralta, J.P., Yap, E.E.S., Panjaitan, F.C.A. \& Chang, Y.W. (2019). Prediction of bioactive peptides from chlorella sorokiniana proteins using proteomic techniques in combination with bioinformatics analyses. International Journal of Molecular Sciences, 20(7). https://doi.org/10.3390/ijms20071786

Tyagi, A., Kapoor, P., Kumar, R., Chaudhary, K., Gautam, A. \& Raghava, G.P.S. (2013). In silico models for designing and discovering novel anticancer peptides. Scientific Reports, 3, 1-8. https://doi.org/10.1038/srep02984

Udenigwe, C.C., Gong, M. \& Wu, S. (2013). In silico analysis of the large and small subunits of cereal RuBisCO as precursors of cryptic bioactive peptides. Process Biochemistry, 48(11), 1794-1799. https://doi.org/10.1016/j.procbio.2013.08.013

Udenigwe, C.C., Okolie, C.L., Qian, H., Ohanenye, I.C., Agyei, D. \& Aluko, R.E. (2017a). Ribulose-1,5-bisphosphate carboxylase as a sustainable and promising plant source of bioactive peptides for food applications. In Trends in Food Science and Technology. https://doi.org/10.1016/j.tifs.2017.09.001

Udenigwe, C.C., Okolie, C.L., Qian, H., Ohanenye, I.C., Agyei, D. \& Aluko, R. E. (2017b). Ribulose-1,5-bisphosphate carboxylase as a sustainable and promising plant source of bioactive peptides for food applications. Trends in Food Science and Technology, 69, 74-82. https://doi.org/10.1016/j.tifs.2017.09.001

Wijesekara, I., Qian, Z.J., Ryu, B., Ngo, D.H. \& Kim, S.K. (2011). Purification and identification of antihypertensive peptides from seaweed pipefish (Syngnathus schlegeli) muscle protein hydrolysate. Food Research International, 44(3), 703-707. https://doi.org/10.1016/j.foodres.2010.12.022

Yuan, X.H., Yao, C., Oh, J.H., Park, C.H., Tian, Y.D., Han, M., Kim, J.E., Chung, J.H., Jin, Z.H. \& Lee, D.H. (2016). Vasoactive intestinal peptide stimulates melanogenesis in B16F10 mouse melanoma cells via CREB/MITF/tyrosinase signaling. Biochemical and Biophysical Research Communications, 477(3), 336-342. https://doi.org/10.1016/j.bbrc.2016.06.105

Zhou, P., Yang, C., Ren, Y., Wang, C. \& Tian, F. (2013). What are the ideal properties for functional food peptides with antihypertensive effect? A computational peptidology approach. Food Chemistry, 141(3), 2967-2973. https://doi.org/10.1016/j.foodchem.2013.05.140 